\title{
Leaflet suspension to the contralateral annulus to address restriction or tethering-induced mitral and tricuspid regurgitation in children: results of a case-control study
}

\author{
Patrick O. Myers, MD, ${ }^{\text {a,b }}$ Jan T. Christenson, MD, ${ }^{a}$ Mustafa Cikirikcioglu, MD, PhD, ${ }^{\text {a }}$ Cécile Tissot, MD, ${ }^{\mathrm{c}}$ \\ Yacine Aggoun, $\mathrm{MD},{ }^{\mathrm{c}}$ and Afksendiyos Kalangos, $\mathrm{MD}, \mathrm{PhD}^{\mathrm{a}}$
}

\begin{abstract}
Objectives: Acceptable coaptation cannot always be obtained using standard repair techniques. We assessed the safety and mid-term results using a novel technique to address leaflet retraction or tethering in children with type III mitral or tricuspid regurgitation as an addition to standard valve repair techniques.
\end{abstract}

\begin{abstract}
Methods: Forty children were included, 36 for the mitral valve and 4 for the tricuspid valve, with a mean age of $11.3 \pm 3.9$ years. A polypropylene suture was placed on the free edge of the retracted or tethered leaflet segment and anchored to the atrial side of the opposite annulus. This avoided valve replacement in all patients. An additional 40 children were matched for age, etiology, leaflet retraction or tethering, and surgery in which the suspension stitch was not used and constituted the control group.

Results: The mean aortic crossclamp and cardiopulmonary bypass time was $36 \pm 9$ and $57 \pm 9$ minutes, respectively. No early or late deaths occurred. At discharge, no patient had more than mild regurgitation with a gradient of $4.4 \pm 2.4 \mathrm{~mm} \mathrm{Hg}$ in the mitral position and $2 \pm 1.75 \mathrm{~mm} \mathrm{Hg}$ in the tricuspid position. The results were not significantly different than those of the control group. During a follow-up of $37.7 \pm 18.4$ months, 3 patients required reoperation for mitral valve replacement in the suspension stitch group and 2 within the control group. At echocardiography of the remaining patients, the repair remained stable, with no suspension suture breakage.
\end{abstract}

Conclusions: This suspension technique improved coaptation and resulted in avoidance or delay of valve replacement in patients with type III regurgitation, with an acceptable transvalvular gradient in most patients that did not significantly increase with growth. (J Thorac Cardiovasc Surg 2010;140:1110-6)

Video clip is available online.

Mitral and tricuspid valve repair, if technically feasible, remains the procedure of choice for most etiologies of mitral and tricuspid regurgitation. However, when the leaflets are retracted or tethered as in type III regurgitation, acceptable coaptation cannot always be obtained using standard repair techniques, as described by Carpentier, ${ }^{1}$ such as ring annuloplasty, leaflet shaving, resection of the retracted secondary or primary chordae tendineae, and pericardial patch leaflet augmentation. Several alternate techniques have

From the Division of Cardiovascular Surgery, ${ }^{\text {a }}$ Geneva University Hospitals, Geneva, Switzerland; the Division of Cardiac Surgery, ${ }^{\mathrm{b}}$ Brigham and Women's Hospital and Harvard Medical School, Boston, Mass; the Pediatric Cardiology Unit, ${ }^{\mathrm{c}}$ Children's University Hospital, Geneva, Switzerland.

Disclosures: None.

Read at the 90th Annual Meeting of The American Association for Thoracic Surgery, Toronto, Ontario, Canada, May 1-5, 2010.

Received for publication March 27, 2010; revisions received July 30, 2010; accepted for publication Aug 9, 2010; available ahead of print Sept 17, 2010.

Address for reprints: Patrick O. Myers, MD, Division of Cardiovascular Surgery, Geneva University Hospitals and School of Medicine, 4, rue Gabrielle-PerretGentil, 1211 Geneva 14, Switzerland (E-mail: patrick.myers@hcuge.ch).

$0022-5223 / \$ 36.00$

Copyright (C) 2010 by The American Association for Thoracic Surgery doi: $10.1016 /$ j.jtcvs.2010.08.015

been proposed to specifically address retraction or tethering, such as papillary muscle relocation ${ }^{2-4}$ edge-to-edge (Alfieri) repair, ${ }^{5}$ and ventricular remodeling. ${ }^{6,7}$

We have previously reported our initial experience with suspension of the retracted posterior leaflet free edge to the ipsilateral annuloplasty ring in 10 rheumatic patients. ${ }^{8}$ This suspension stitch was conceived by one of us (A.K.) and refined by suspending the leaflet free edge to the contralateral annulus, to allow for better coaptation. The aim of the present study was to assess the safety and mid-term results using this novel technique to address leaflet restricted motion or tethering of any etiology in children.

\section{MATERIALS AND METHODS}

The local Ethics Committee reviewed and approved the study, and patient consent was waived.

\section{Demographics}

From March 2003 through May 2009, 40 consecutive children who had undergone mitral or tricuspid repair for regurgitation were found to have unacceptable residual regurgitation after the use of standard repair techniques such as described by Carpentier. ${ }^{1}$ These children required leaflet suspension to the contralateral annulus (described in the present study) as a salvage procedure to avoid potential valve replacement. A portion of these patients had been reported previously in other studies..$^{9-12}$

Of these 40 children, 36 had had this technique applied to the mitral valve (rheumatic mitral regurgitation in 22 , congenital in 11 , functional 


\section{Abbreviations and Acronyms \\ $\mathrm{CI}=$ confidence interval \\ $\mathrm{HR}=$ hazard ratio}

in 1 , degenerative in 1 , and endocarditis in 1) and 4 to the tricuspid valve (dysplastic tricuspid valve in 2 and Ebstein's anomaly in 2). Their mean age was $11.4 \pm 3.9$ years. For the purpose of evaluating this novel technique, 40 additional children who had undergone similar operations and had been matched for age, etiology, and mechanism of valve regurgitation were used as the control group. The children in the control group had not required techniques beyond the traditional mitral or tricuspid repair techniques $^{1}$ and had been identified within the same study period. All the patients in both groups presented with type I mitral or tricuspid regurgitation because of annulus dilatation, with the exception of 1 patient with hammock mitral valve (see below), and type III regurgitation due to tethering or retraction. These findings were confirmed by preoperative echocardiography and intraoperative valve analysis. The patient demographics of the entire study population are summarized in Table 1 .

\section{Operative Technique}

Cardiopulmonary bypass was established using ascending aortic and bicaval cannulation. All patients underwent surgery by the same surgeon (A.K.) at normothermia. Myocardial protection consisted of cold antegrade hyperkalemic crystalloid cardioplegia, repeated every 20 minutes. The mitral valve was explored through a left atriotomy performed in the interatrial groove. Each structure of the mitral valve was analyzed systematically. In all patients, with the exception of 2, annuloplasty was performed using a Bioring Kalangos biodegradable ring (Bioring SA, Lonay, Switzerland), as described previously., ${ }^{9,13}$ The mean annuloplasty ring size was $26.6 \pm 3.6$ (range, 16-34) in the mitral position (suspension group, $26.2 \pm 3.9$; control group, $26.9 \pm 3.3 ; P=.42$ ), with a mean patient age of $11.3 \pm 4$ years. The mean annuloplasty ring size was $27 \pm 3.6$ (range, 24-34) in the tricuspid position (suspension group, $24.5 \pm 1.0$; control group, $29.5 \pm$ 3.4; $P=.03$ ), with a mean patient age of $11.6 \pm 3.2$ years. Two patients did not undergo annuloplasty during the studied operation. One patient underwent mitral valve repair in heart failure during the acute phase of rheumatic heart disease. The repair included annuloplasty with a biodegradable ring. Although significant posterior leaflet retraction was noted at that time, suspension was not considered because of the extreme fragility of the inflamed tissues. The patient developed progressively moderate-to-severe regurgitation and underwent reoperation 3 months after the primary operation. The suspension stitch was successfully used on the healed, retracted posterior leaflet segments, avoiding valve replacement. This second operation was included in the suspension stitch group. The second patient presented with a hammock mitral valve, with significant mitral stenosis (mean transvalvular gradient $20 \mathrm{~mm} \mathrm{Hg}$ ). Commissurotomy, leaflet mobilization by papillary muscle splitting, and suspension of $\mathrm{P} 2-\mathrm{P} 3$ were performed. Annuloplasty was not considered because of concerns of stenosis.

The surgical procedures included leaflet-level chordal shortening at the free edge of the prolapsing segments, chordal transfer, secondary or primary posterior chordal resection, commissurotomy, commissuroplasty, triangular resection, sliding plasty, and vegetation resection (Table 2). Secondary chordal transfer to the primary position was mainly used in cases of anterior leaflet prolapse due to chordal rupture or cases of anterior leaflet pseudoprolapse due to restricted posterior leaflet motion.

After completing these procedures, water testing revealed significant residual regurgitation owing to persistent restricted motion or tethering of a leaflet in the 40 patients in the suspension stitch group. These patients were considered candidates for valve replacement. Our additional tech-
TABLE 1. Patient characteristics

\begin{tabular}{|c|c|c|c|c|}
\hline Variable & Total & $\begin{array}{l}\text { Suspension } \\
\text { stitch group }\end{array}$ & $\begin{array}{c}\text { Control } \\
\text { group }\end{array}$ & $\begin{array}{r}P \\
\text { valu }\end{array}$ \\
\hline Patients (n) & 80 & 40 & 40 & \\
\hline Age (y) & $11.3 \pm 3.9$ & $11.4 \pm 3.9$ & $11.2 \pm 4.0$ & .80 \\
\hline Males & $35(43.8 \%)$ & $15(37.5 \%)$ & $20(50 \%)$ & .27 \\
\hline Previous cardiac operation $\ddagger$ & $12(15 \%)$ & $7(17.5 \%)$ & $5(12.5 \%)$ & .76 \\
\hline Mitral valve repair & $7(8.8 \%)$ & $3(7.5 \%)$ & $4(10 \%)$ & 1.0 \\
\hline Aortic valve repair & $1(1.3 \%)$ & $1(2.5 \%)$ & $0(0 \%)$ & 1.00 \\
\hline AVC defect repair & $2(2.5 \%)$ & $1(2.5 \%)$ & $1(2.5 \%)$ & 1.00 \\
\hline Coarctation repair & $2(2.5 \%)$ & $2(5 \%)$ & $0(0 \%)$ & .49 \\
\hline Subaortic stenosis repair & $1(1.3 \%)$ & $1(2.5 \%)$ & $0(0 \%)$ & 1.00 \\
\hline $\begin{array}{l}\text { Congenital coronary } \\
\text { anomaly repair } \S\end{array}$ & $2(2.5 \%)$ & $1(2$. & 1( & 1 \\
\hline Mitral valve & $72(90 \%)$ & $36(90 \%)$ & $36(90 \%)$ & 1.00 \\
\hline Rheumatic & $44(55 \%)$ & $22(55 \%)$ & $22(55 \%)$ & 1.00 \\
\hline Congenital & $22(27.5 \%)$ & $11(27.5 \%)$ & $11(27.5 \%)$ & 1.00 \\
\hline Functional & $2(2.5 \%)$ & $1(2.5 \%)$ & $1(2.5 \%)$ & 1.00 \\
\hline Degenerative & $2(2.5 \%)$ & $1(2.5 \%)$ & $1(2.5 \%)$ & 1.00 \\
\hline Endocarditis & $2(2.5 \%)$ & $1(2.5 \%)$ & $1(2.5 \%)$ & 1.00 \\
\hline Tricuspid valve & $8(10 \%)$ & $4(90 \%)$ & $4(90 \%)$ & 1.00 \\
\hline Dysplastic & $4(5 \%)$ & $2(5 \%)$ & $2(5 \%)$ & 1.00 \\
\hline Ebstein's anomaly & $4(5 \%)$ & $2(5 \%)$ & $2(5 \%)$ & 1.00 \\
\hline Concomitant procedure & $29(36 \%)$ & $16(40 \%)$ & $13(32.5 \%)$ & .6 \\
\hline Aortic valve repair & $6(7.5 \%)$ & $2(5 \%)$ & $4(10 \%)$ & .68 \\
\hline Aortic valve replacement & $3(3.8 \%)$ & $1(2.5 \%)$ & $2(5 \%)$ & 1.00 \\
\hline Tricuspid valve repair & $11(13.8 \%)$ & $6(15 \%)$ & $5(12.5 \%)$ & 1.00 \\
\hline Bidirectional Glenn shunt & $2(2.5 \%)$ & $2(5 \%)$ & $0(0 \%)$ & .45 \\
\hline VSD repair & $1(1.3 \%)$ & $1(2.5 \%)$ & $0(0 \%)$ & 1.00 \\
\hline ASD repair & $3(3.8 \%)$ & $2(5 \%)$ & $1(2.5 \%)$ & 1.00 \\
\hline PFO repair & $1(1.3 \%)$ & $1(2.5 \%)$ & $0(0 \%)$ & 1.00 \\
\hline Partial AVC defect repair & $1(1.3 \%)$ & $0(0 \%)$ & $1(2.5 \%)$ & 1.00 \\
\hline Cox-Maze procedure & $4(5 \%)$ & $1(2.5 \%)$ & $3(7.5 \%)$ & .62 \\
\hline ALCAPA repair & $1(1.3 \%)$ & $1(2.5 \%)$ & $0(0 \%)$ & 1.00 \\
\hline Subaortic stenosis repair & $1(1.3 \%)$ & $0(0 \%)$ & $1(2.5 \%)$ & 1.0 \\
\hline
\end{tabular}

*Independent samples Student $t$ test between suspension stitch and control groups. $\dagger$ Fisher's exact test. ‡Performed at another institution. §Congenital coronary anomalies included an ALCAPA repair and unroofing of congenital ostial left main coronary artery stenosis. $A V C$, atrioventricular canal; VSD, ventricular septal defect; $A S D$, atrial septal defect; $P F O$, patent foramen ovale; $A L C A P A$, anomalous left coronary artery originating from the pulmonary artery.

nique was applied first as a salvage procedure to potentially avoid replacement. A 5-0 polypropylene suture was placed on the free edge of the retracted leaflet segment responsible for residual regurgitation and then anchored to the atrial side of the contralateral annulus. An autologous pericardial pledget was used if the annular tissue appeared fragile (Video 1 and Figure 1).

The length of this horizontal mattress suture was regulated while tying its 2 strands together on the contralateral annulus. This allowed the retracted or tethered leaflet to be brought up and rest closer to the natural coaptation plane. The primary aim was to achieve coaptation, rather than an anatomic function of the retracted or tethered leaflet. The risk of leaflet abrasion or suture tearing over time was regarded as low, because the suspended leaflet was not a part of the leaflet movement and the suture was placed to resist the relatively low diastolic pressures. Two patients required posterior mitral commissure suspension, and 34 required posterior mitral leaflet suspension (Table 3). Of the 4 patients who underwent tricuspid repair, 3 required septal leaflet suspension and 1 required posterior leaflet suspension. 
TABLE 2. Operative data

\begin{tabular}{llllr}
\hline \multicolumn{1}{c}{ Variable } & $\begin{array}{c}\text { Entire study } \\
\text { population }\end{array}$ & $\begin{array}{l}\text { Stitch group } \\
\text { group }\end{array}$ & $\begin{array}{c}\text { Control } \\
\text { value }\end{array}$ \\
\hline Aortic crossclamp (min) & $36.0 \pm 9.3$ & $35.4 \pm 10.3$ & $36.6 \pm 8.3$ & $.57 *$ \\
Cardiopulmonary & $56.9 \pm 9.4$ & $57.9 \pm 8.3$ & $55.8 \pm 10.4$ & $.31 *$ \\
bypass (min) & & & & \\
Valve repair technique & & & & \\
Ring annuloplasty & $78(97.5 \%)$ & $38(95 \%)$ & $40(100 \%)$ & $.49 \dagger$ \\
Leaflet-level chordal & $18(22.5 \%)$ & $5(12.5 \%)$ & $13(32.5 \%)$ & $.06 \dagger$ \\
$\quad$ shortening & & & & \\
Leaflet indentation & $46(57.5 \%)$ & $20(43.5 \%)$ & $26(65 \%)$ & $.26 \dagger$ \\
$\quad$ closure & & & & \\
Leaflet cleft closure & $14(17.5 \%)$ & $7(17.5 \%)$ & $7(17.5 \%)$ & $1.00 \dagger$ \\
Commissuroplasty & $22(27.5 \%)$ & $6(15 \%)$ & $16(40 \%)$ & $.02 \dagger$ \\
Primary chordea & $11(13.8 \%)$ & $5(12.5 \%)$ & $6(15 \%)$ & $1.00 \dagger$ \\
$\quad$ resection & & & & \\
Secondary chordae & $10(12.5 \%)$ & $3(7.5 \%)$ & $7(17.5 \%)$ & $.31 \dagger$ \\
$\quad$ resection & & & & \\
Chordal transfer & $11(13.8 \%)$ & $5(12.5 \%)$ & $6(15 \%)$ & $1.00 \dagger$ \\
Artificial chordae & $1(1.3 \%)$ & $0(0 \%)$ & $1(2.5 \%)$ & $1.00 \dagger$ \\
Triangular leaflet & $3(3.8 \%)$ & $3(7.5 \%)$ & $0(0 \%)$ & $.24 \dagger$ \\
$\quad$ resection & & & & \\
Sliding fundoplasty & $6(7.5 \%)$ & $0(0 \%)$ & $6(15 \%)$ & $.03 \dagger$ \\
Leaflet pericardial & $1(1.3 \%)$ & $0(0 \%)$ & $1(2.5 \%)$ & $1.00 \dagger$ \\
$\quad$ patch augmentation & & & & \\
Papillary muscle & $11(13.8 \%)$ & $7(17.5 \%)$ & $4(10 \%)$ & $.52 \dagger$ \\
$\quad$ fenestration & & & & \\
Commissurotomy & $8(10 \%)$ & $4(10 \%)$ & $4(10 \%)$ & $1.00 \dagger$ \\
Vegetation resection & $1(1.3 \%)$ & $1(2.5 \%)$ & $0(0 \%)$ & $1.00 \dagger$ \\
Ebstein's anomaly repair & $4(5 \%)$ & $2(5 \%)$ & $2(5 \%)$ & $1.00 \dagger$ \\
\hline
\end{tabular}

*Independent sample $t$ test between suspension stitch and control groups. †Fisher's exact test.

At completion of the repair, valve competence was tested using a bulb syringe to inject saline solution into the left or right ventricle. Concomitant procedures were performed in 29 patients (Table 1). All patients underwent intraoperative transesophageal echocardiography before skin incision and after termination of cardiopulmonary bypass to evaluate the valvular repair.

\section{Follow-up}

Transthoracic echocardiography was performed in all patients before surgery, before discharge from the hospital, and at 3 to 6 weeks postoperatively in the outpatient clinic of our institution before returning to their referring cardiologist or countries of origin. The Doppler echocardiographic grade of mitral regurgitation was measured using color Doppler flow and graded according to the width and length of the regurgitant jet in the left atrium (grade I-IV). The mean gradient across the mitral valve was estimated by measuring the peak diastolic velocity from the Doppler studies in a 4-chamber view. All 80 patients $(100 \%)$ were followed up in outpatient clinics by cardiologists in their countries of origin, who periodically informed us of their patient's evolution by completing a questionnaire that included clinical, echocardiographic, and medication information. Follow-up for the present study was continued until December 2009. We followed the standard published guidelines for reporting the freedom from valve-related events. ${ }^{14}$

\section{Statistical Analysis}

Statistical analyses were performed using the Statistical Package for Social Sciences software (SPSS Inc, Chicago, Ill). The data are presented as the mean \pm standard deviation. Continuous variables were analyzed using the independent-samples Student $t$ test and categorical variables using Fisher's exact test. Actuarial estimates were calculated using the KaplanMeier method, and differences between curves were assessed using the $\log$-rank test. Univariate and stepwise Cox multivariate regression analyses were used to identify the independent predictors of the need for late reoperation and transvalvular gradients of $7 \mathrm{~mm} \mathrm{Hg}$ or greater, as well as to assess whether inclusion in the suspension stitch group was a predictor of these 2 outcome measures. The preoperative and operative variables with a univariate $P$ value of $<.1$ and those judged to be clinically important (age, gender, valve treated, previous cardiac surgery, concomitant cardiac surgery, suspension stitch group vs control group) were entered into the Cox models. Hazards ratios (HRs) for the risk factors for reoperation were calculated using univariate and multivariate Cox proportional hazards estimates. All statistical tests were 2-tailed.

\section{RESULTS \\ Early Outcomes}

The mean aortic crossclamp and cardiopulmonary bypass time was $36 \pm 9.3$ and $56.9 \pm 9.4$ minutes, respectively, with no significant difference between the suspension stitch and control groups (crossclamp time, $35.4 \pm 10.3$ and $36.6 \pm 8.3$ minutes; $P=.57$; cardiopulmonary bypass time, $57.9 \pm 8.3$ and $55.8 \pm 10.4$ minutes; $P=.31$, respectively). After applying the suspension stitch, valve replacement was avoided in all 40 patients. No hospital deaths or major postoperative morbidity occurred. No patients required reoperation within 30 days.

\section{Late Outcomes}

Follow-up was complete for all patients. The mean and median follow-up period was $37.7 \pm 18.4$ and 37 months, respectively (range, 3 months to 7 years). The median follow-up was 26 months for the suspension stitch group and 41 months for the control group. This difference in median follow-up was because although both groups underwent surgery within the studied period, we started using the suspension technique gradually since 2003, with an exponential increase in its use with time, while the control group underwent surgery more uniformly during the study period. No patients died during follow-up. No thromboembolic or hemorrhagic events had been observed at the latest follow-up examinations.

A total of 5 patients $(6.3 \%)$ with rheumatic mitral regurgitation underwent reoperation for severe mitral valve dysfunction after a mean period of $19.4 \pm 16.7$ months (range, 3-43 months) from the initial mitral valve repair, 3 in the suspension stitch group $(7.5 \%)$ and 2 in the control group $(5 \%)$. The mean period to reoperation was shorter in the suspension stitch group (mean, $8 \pm 5.6$ months; median, 7 months; range, 3-14 months) than in the control group (mean, $36.5 \pm 9.2$ months; median, 36.5 months; range, 30-43 months; $P=.02$ ).

The actuarial rate of freedom from reoperation for significant valve dysfunction was $96 \% \pm 2.2 \%$ at 1 year, $94.2 \% \pm$ $2.9 \%$ at 3 years, and $91.2 \% \pm 4.1 \%$ at 5 years (Figure 2 ). For the suspension stitch group, the rate of freedom from 


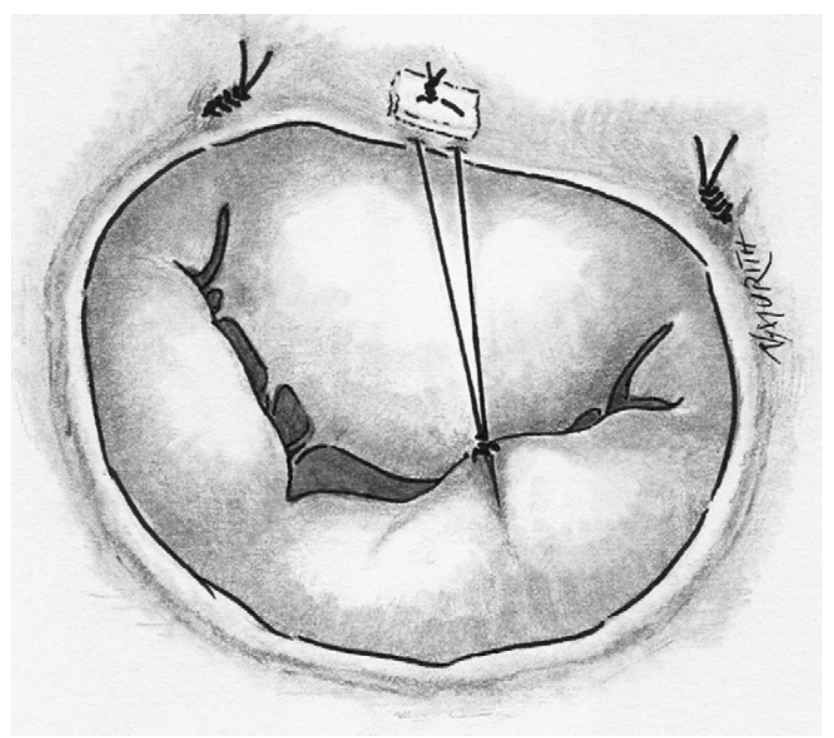

FIGURE 1. Schematic representation of suspension stitch in the mitral position. The P2-P3 junction is suspended using polypropylene suture to the anterior annulus over a pledget, bringing the restricted or tethered leaflet segment up to the coaptation plane.

reoperation was $97.5 \% \pm 2.5 \%$ at 6 months and $92.4 \% \pm$ $4.2 \%$ at 1 year and remained unchanged to 7 years. For the control group, the freedom from reoperation rate was $96.6 \% \pm 3.4 \%$ at 6 months and 1 and 3 years and was $91.2 \% \pm 6.1 \%$ at 5 years. The difference between the 2 groups was not statistically significant (log-rank test, $P=.52)$. On Cox proportional hazards modeling, the suspension stitch was not a predictor of reoperation (univariate HR, 0.56; $95 \%$ confidence interval $[\mathrm{CI}], 0.09-3.38 ; P=.53$; multivariate-adjusted $\mathrm{HR}, 1.89 ; 95 \% \mathrm{CI}, \quad 0.29-12.06$; $P=.51)$.

\section{Valve Function and Transvalvular Gradients}

Of the patients who required the suspension stitch, 1 patient in the mitral group had mild regurgitation at discharge and 39 presented with trivial or no regurgitation, with a mean transvalvular gradient of $4.4 \pm 2.4 \mathrm{~mm} \mathrm{Hg}$ (range,

TABLE 3. Leaflet suspension

\begin{tabular}{lc}
\hline Leaflet segment suspended & $\mathbf{n}(\%)$ \\
\hline Mitral valve & \\
P1 & $4(10 \%)$ \\
P1-P2 & $3(7.5 \%)$ \\
P2 & $3(7.5 \%)$ \\
P2-P3 & $16(40 \%)$ \\
P3 & $6(15 \%)$ \\
P1 and P3 & $2(5 \%)$ \\
Posterior commissure & $2(5 \%)$ \\
Tricuspid valve & \\
Posterior leaflet & $1(2.5 \%)$ \\
Septal leaflet & $3(7.5 \%)$ \\
\hline
\end{tabular}

1.3-11; $>7$ in 3 patients). All patients in the suspension stitch group had no or trivial tricuspid regurgitation, with a transvalvular gradient of $2 \pm 1.75 \mathrm{~mm} \mathrm{Hg}$. In the control group, 2 patients in the mitral group had mild regurgitation, with a transvalvular gradient of $3.3 \pm 2.6$ (range, $2-10 ;>7$ in $2 ; P=.09$; compared with the suspension group). No patient in the control group had tricuspid regurgitation, with a transvalvular gradient of $3.7 \pm 1.7 \mathrm{~mm} \mathrm{Hg}(P=.14)$. The echocardiograms of the 75 patients who did not require reoperation showed the repair remained stable. In the suspension group, the mean transvalvular gradient slightly decreased to $4.2 \pm 1.6 \mathrm{~mm} \mathrm{Hg}$ (range, $2-11 ;>7$ in 1 ) for the mitral valve and was unchanged at $2 \pm 1.75 \mathrm{~mm} \mathrm{Hg}$ for the tricuspid valve, with no suspension suture breakage. In the control group, the mean transvalvular gradient decreased to $2.8 \pm 2.3 \mathrm{~mm} \mathrm{Hg}$ (range, $1-10 ;>7$ in 2; $P=.005$ compared with the suspension group) for the mitral valve and $3.6 \pm 1.5 \mathrm{~mm} \mathrm{Hg}$ for the tricuspid valve $(P=1.00)$. The left ventricular systolic dimensions (suspension stitch group, $4.6 \pm 0.4 \mathrm{~cm}$ vs control group, $4.7 \pm 0.4 \mathrm{~cm} ; P=.9)$ and diastolic dimensions $(2.8 \pm 0.5$ cm vs $2.9 \pm 0.4 \mathrm{~cm}$, respectively; $P=.74$ ) were not significantly different between the 2 groups at the last follow-up visit. On Cox proportional hazards modeling, the suspension stitch was not a predictor of a transvalvular gradient of $7 \mathrm{~mm} \mathrm{Hg}$ or more at latest follow-up (univariate HR, $0.98 ; 95 \%$ CI, 0.22-4.37; $P=.97$; multivariate-adjusted HR, $1.68 ; 95 \% \mathrm{CI}, 0.3-9.3 ; P=.56$ ). Older age at surgery (multivariate-adjusted HR, 0.52; 95\% CI, 0.31-0.89; $P=.02$ ) and previous cardiac surgery (multivariateadjusted HR, 0.004; 95\% CI, 0-0.71; $P=.04$ ) were independent predictors of this outcome measure.

\section{DISCUSSION}

Surgical management of mitral and tricuspid regurgitation in the young is problematic because of the lack of an ideal valve substitute within this age group. Prosthetic valves have significant drawbacks, including suboptimal preservation of ventricular function, reduced survival, problems related to growth and future pregnancy, difficult lifelong anticoagulation and panus formation for mechanical valves, and rapid deterioration and calcification for bioprosthetic valves. ${ }^{15}$ The long-term results of surgery for mitral regurgitation have shown that repair is preferable over replacement in terms of survival and thromboembolic and bleeding complications. ${ }^{16}$ A restricted posterior leaflet is characteristic in rheumatic mitral regurgitation. ${ }^{8,17}$ Tethering is often one of the mechanisms responsible for regurgitation in functional and dysplastic mitral and tricuspid regurgitation. ${ }^{18,19}$ Both of these mechanisms of type III regurgitation are not addressed with ring annuloplasty, although newer 3dimensional rigid rings have been developed for this reason and are currently being evaluated in adults. ${ }^{20}$ One of the tenets of Carpentier's strategy toward valve repair 


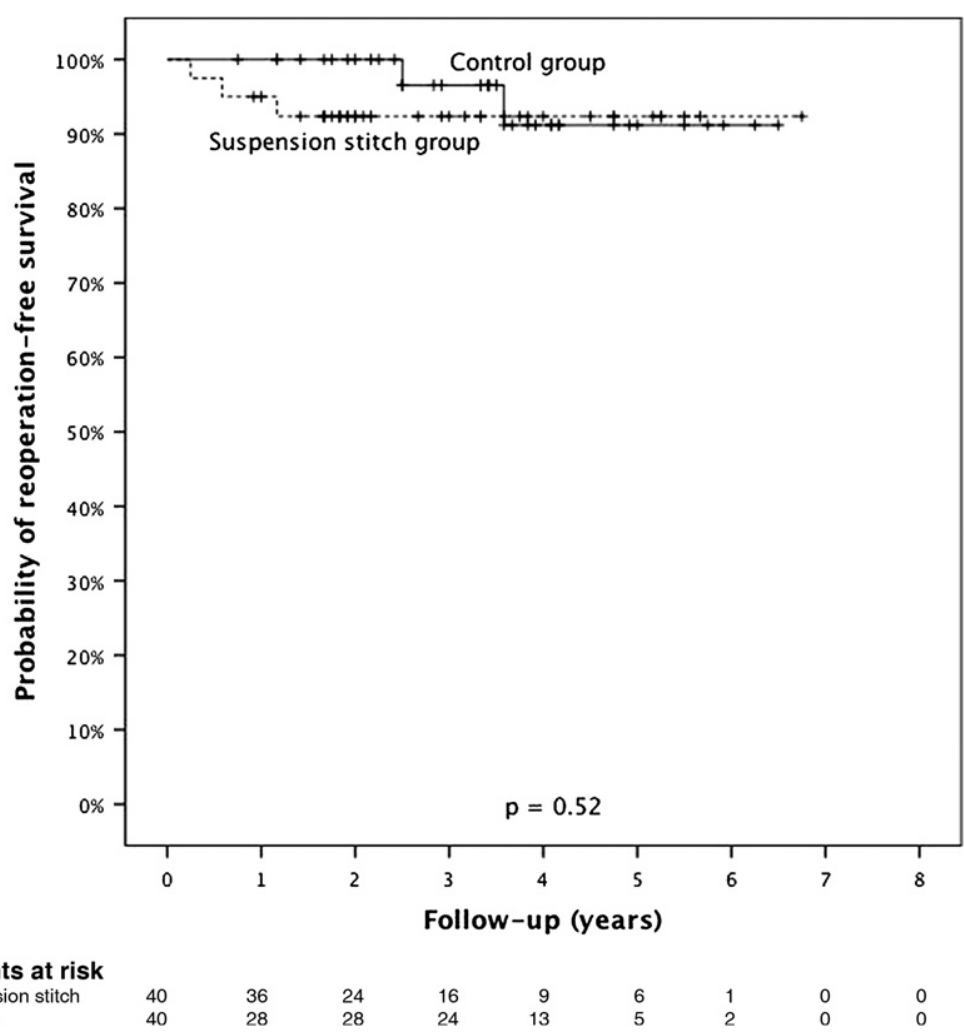

FIGURE 2. Survival curves after mitral or tricuspid valve repair in 80 children. Difference between curves did not reach statistical significance (log-rank test, $P=.52$ ).

has been to provide a functional, rather than an anatomic, repair. ${ }^{1}$ This often transforms the mitral valve into a functionally unicuspid valve with adequate leaflet coaptation from full motion of the anterior leaflet. We postulated that by bringing the restricted posterior leaflet up to the coaptation plane, regurgitation could be improved sufficiently to avoid valve replacement in patients with rheumatic mitral posterior leaflet retraction. This was first done by anchoring sutures on the free edge of the posterior leaflet, which were brought up to the posterior annuloplasty ring and tied down. ${ }^{8}$ We refined this technique, postulating that by bringing this suture across the valve to the opposing annulus, better coaptation could be obtained. This technique has subsequently been used in instances of leaflet restriction or tethering for disorders other than rheumatic regurgitation, as reported in the present study.

One issue during valve repair in children is the durability of the repair, in part because of the very long life expectancy of the patient, and in part because of the somatic growth of the child. This issue is a particular concern because of the possibility of iatrogenic-induced stenosis with ring annuloplasty and this suspension stitch. During a mean follow-up of just longer than 3 years, no patient developed symptomatic mitral or tricuspid stenosis, and the transvalvular gradients decreased from a mean of $4.4 \pm 2.4 \mathrm{~mm} \mathrm{Hg}$ to $4.2 \pm 1.6$ $\mathrm{mm} \mathrm{Hg}$ in the mitral position and remained stable at $2 \pm 1.75$ $\mathrm{mm} \mathrm{Hg}$ in the tricuspid position. In the control group, the mean gradients decreased from $3.3 \pm 2.6$ to $2.8 \pm 2.3 \mathrm{~mm}$ $\mathrm{Hg}$ in the mitral position and $3.7 \pm 1.7$ to $3.6 \pm 1.5 \mathrm{~mm}$ $\mathrm{Hg}$ in the tricuspid position. Although the relative change in the gradient was not significant within each group and position, the gradients were significantly lower statistically in the control group than in the suspension stitch group in the mitral position at the latest follow-up. This stability in the transvalvular gradients in both groups was consistent with our experience using the Bioring Kalangos biodegradable annuloplasty ring in children in the mitral position. ${ }^{9}$ It is important to note that all the patients in the present study, with the exception of 1 , underwent annuloplasty with a Bioring Kalangos biodegradable ring. This could explain this decrease in gradients during follow-up. We previously showed that of 220 children with rheumatic mitral regurgitation, those who underwent annuloplasty with a CarpentierEdwards ring had a mean increase of $1.8 \mathrm{~mm} \mathrm{Hg}$ during the first year compared with $0.5 \mathrm{~mm} \mathrm{Hg}$ in children who received a biodegradable annuloplasty ring. ${ }^{9}$ In an experimental juvenile pig model, in which the pigs' mean weight increased by $500 \%$ during the year of follow-up after Bioring implantation, transvalvular gradients remained stable and the measured valve area showed regular somatic growth. ${ }^{13}$ Mrowczynski and colleagues showed that the tricuspid annulus continues to grow after Bioring implantation 
along the curve of normal somatic tricuspid annular growth in children with congenital tricuspid regurgitation (unpublished data, presented at the Society of Thoracic Surgeons 2010 Annual Meeting, Poster P48). It is thus possible that the relatively low rates of reoperation and elevated transvalvular gradients were favorably biased by the use of this biodegradable ring. Thus, caution is advised if applying the results of the present study to other annuloplasty devices or techniques.

The present study was limited by the relatively small sample size, retrospective, nonrandomized design, and midterm follow-up. Both groups were matched for the presence of leaflet restricted motion or tethering, age, valve treated, and etiology of valve disease and no significant differences in the preoperative patient characteristics were found. However, the control group was not exactly similar because the standard repair techniques were sufficient to relieve leaflet restriction or tethering without resorting to our additional suspension stitch in the control group. Furthermore, the sample size did not allow for propensity score analysis. The use of the suspension stitch was determined by subjective criteria at water testing of the mitral or tricuspid valve when the standard techniques were not sufficient to decrease the degree of residual insufficiency. Thus, a selection bias could not be ruled out. The multivariate models used for Cox proportional hazards modeling were limited by the number of events. Only 5 events occurred for 8 degrees of freedom in the models using reoperation as an outcome and 7 events in the models using a high transvalvular gradient as an outcome. However, 5 to 10 times more events than degrees of freedom are usually recommended. Finally, follow-up echocardiographic data were mostly interpreted and analyzed by the referring cardiologist in the patients' country of origin. This introduced the risk of estimator bias, because the echocardiographic images could not be interpreted by an independent echocardiography laboratory unaware of the surgery and clinical outcome. Furthermore, more detailed data, such as the right ventricular dimensions, or quantitative methods of grading regurgitation, such as the actual width of the vena contracta or proximal isovelocity surface area, could not be obtained in a large proportion of patients.

\section{CONCLUSIONS}

The suspension technique described is simple and safe. It moves the retracted or tethered leaflet up to the coaptation plane, thus creating a larger coaptation area that can eliminate regurgitation. In our experience of 40 children, adequate leaflet coaptation was achieved and allowed the avoidance of valve replacement. This result was maintained in all but 3 children during a median follow-up of 37 months and extending up to 7 years. No technical failures of the stitch and no leaflet abrasion occurred during follow-up. Also, stenosis did not develop. These results were comparable to the results in the control group.

\section{References}

1. Carpentier A. Cardiac valve surgery-The "French correction." J Thorac Car diovasc Surg. 1983;86:323-37.

2. Jensen H, Jensen MO, Smerup MH, Vind-Kezunovic S, Ringgaard S, Andersen NT, et al. Impact of papillary muscle relocation as adjunct procedure to mitral ring annuloplasty in functional ischemic mitral regurgitation. Circulation. 2009;120(11 Suppl):S92-8.

3. Hung J, Solis J, Guerrero JL, Braithwaite GJ, Muratoglu OK, Chaput M, et al. A novel approach for reducing ischemic mitral regurgitation by injection of a polymer to reverse remodel and reposition displaced papillary muscles. Circulation. 2008;118(14 Suppl):S263-9.

4. Hvass U, Joudinaud T. The papillary muscle sling for ischemic mitral regurgitation. J Thorac Cardiovasc Surg. 2010;139:418-23.

5. De Bonis M, Lapenna E, La Canna G, Grimaldi A, Maisano F, Torracca L, et al. A novel technique for correction of severe tricuspid valve regurgitation due to complex lesions. Eur J Cardiothorac Surg. 2004;25:760-5.

6. Kappert U, Tugtekin SM, Ouda A, Alexiou K, Schmeisser A, Schoen S, et al. Right ventricular reduction as an adjunct procedure in tricuspid valve repair. Ann Thorac Surg. 2008;85:e27-9.

7. Acker MA, Bolling S, Shemin R, Kirklin J, Oh JK, Mann DL, et al. Mitral valve surgery in heart failure: Insights from the Acorn Clinical Trial. J Thorac Cardiovasc Surg. 2006;132:568-77, 77e1-4.

8. Sierra J, Lahlaidi NH, Christenson JT, Kalangos A. Mitral valve insufficiency: suspension of the posterior leaflet to the mitral annuloplasty ring. Ann Thorac Surg. 2008;85:e6-8.

9. Kalangos A, Christenson JT, Beghetti M, Cikirikcioglu M, Kamentsidis D, Aggoun Y. Mitral valve repair for rheumatic valve disease in children: Midterm results and impact of the use of a biodegradable mitral ring. Ann Thorac Surg. 2008;86:161-9.

10. Myers PO, Beghetti M, Kalangos A. Biodegradable mitral annuloplasty for congenital ischemic mitral regurgitation. Thorac Cardiovasc Surg. 2009;57: 363-4.

11. Myers PO, Panos A, Cikirikcioglu M, Kalangos A. Anterior leaflet augmentation to address tethering-induced functional tricuspid regurgitation. Eur J Cardiothorac Surg. 2009;35:194-6.

12. Pektok E, Sierra J, Cikirikcioglu M, Müller H, Myers PO, Kalangos A. Mid-term results of valve repair with a biodegradable annuloplasty ring for acute endocarditis. Ann Thorac Surg. 2010;89:1180-5.

13. Kalangos A, Sierra J, Vala D, Cikirikcioglu M, Walpoth B, Orrit X, et al. Annuloplasty for valve repair with a new biodegradable ring: An experimental study. $J$ Heart Valve Dis. 2006;15:783-90.

14. Akins CW, Miller DC, Turina MI, Kouchoukos NT, Blackstone EH, Grunkemeier GL, et al. Guidelines for reporting mortality and morbidity after cardiac valve interventions. J Thorac Cardiovasc Surg. 2008;135:732-8.

15. Walker WE, Duncan JM, Frazier OH Jr, Livesay JJ, Ott DA, Reul GJ, et al. Early experience with the Ionescu-Shiley pericardial xenograft valve: Accelerated calcification in children. J Thorac Cardiovasc Surg. 1983;86:570-5.

16. Mohty D, Orszulak TA, Schaff HV, Avierinos JF, Tajik JA, Enriquez-Sarano M. Very long-term survival and durability of mitral valve repair for mitral valve prolapse. Circulation. 2001;104(12 Suppl. 1):I1-7.

17. Wong S, French R, Bolson E, McDonald J, Legget M, Sheehan F. Morphologic features of the rheumatic mitral regurgitant valve by three-dimensional echocardiography. Am Heart J. 2001;142:897-907.

18. Magne J, Pibarot P, Dumesnil JG, Senechal M. Continued global left ventricular remodeling is not the sole mechanism responsible for the late recurrence of ischemic mitral regurgitation after restrictive annuloplasty. $J$ Am Soc Echocardiogr 2009;22:1256-64.

19. Kudo M, Yozu R, Aeba R, Kokaji K, Kimura N, Iwanaga S. A case report of surgical correction for congenital mitral regurgitation with subvalvular apparatus abnormality. Gen Thorac Cardiovasc Surg. 2008;56:36-8.

20. Votta E, Maisano F, Bolling SF, Alfieri O, Montevecchi FM, Redaelli A. The Geoform disease-specific annuloplasty system: A finite element study. Ann Thorac Surg. 2007;84:92-101.

\section{Discussion}

Dr Luca Vricella (Baltimore, $M d$ ). I would like to thank the organizing committee for the privilege of starting the discussion on this very interesting series of patients with mitral valve regurgitation and Dr Myers for kindly providing me in advance with the 
manuscript and video for this presentation. Let me congratulate the group in Geneva and Dr Kalangos, in particular, on their outstanding results with mitral valve repair in children. I have a few comments and 3 questions.

This particular technique is really a modified Alfieri suture. The difference is that the posterior leaflet is displaced superiorly and anteriorly rather than creating a double orifice valve. I can see how in patients with isolated posterior leaflet restriction, which was the case, this would have minimal impact on creating stenosis and also only create diastolic stress on the suture. I assume that the suspension is performed in all cases after placement of an annuloplasty ring and immediately after saline testing rather than after a first attempt at weaning from cardiopulmonary bypass. So you are actually testing the valve with a subjective test, and then you come off bypass after putting the stitch, thereby acting on objective data that documents regurgitation. So it might be the annuloplasty band that corrects the regurgitation, rather than your suture, you just do not know.

So, my first question is, in these cases, you used a particular reabsorbable or partial ring with an average size of $26 \mathrm{~mm}$ in a group of patients with a mean age of 11 years. Do you think that a similar result could have been achieved by slightly undersizing the annuloplasty? In other words, how significant was the contribution of type I regurgitation, because you brought the diameters down to $26 \mathrm{~mm}$, which is a size very close to an adult-size mitral valve? Also, in the manuscript, as you said, these patients all had type I and type III abnormalities.

Dr Cikirikcioglu. Thank you very much for your comments. The mean size of the biodegradable ring in this series was 26 . However, when we looked at all the patients, there are some smaller sizes, used in younger children, which are not available in traditional rings. However, the use of the appropriate biodegradable ring size allows us to keep the transmitral gradient stable during the follow-up period. In our opinion, it is not really the best option to ensure a better coaptation surface only by using undersized valvuloplasty in these patients in whom the posterior leaflet is severely retracted and tethered.

Dr Vricella. But you actually did do that in 40 patients in this series, right, you just did an annuloplasty ring?

Dr Cikirikcioglu. Yes, with associated repair techniques.

Dr Vricella. The second question is: At the time of the operation in the suspension stitch group, you performed secondary and primary chordal shortening and triangular leaflet, resection in a substantial number of patients. These techniques are also often used in patients who have type II motion abnormality. So the question here is you also performed leaflet indentation closure and commissuroplasty in $43 \%$ and $15 \%$ of patients in this group. So, these can actually pull tissue away from the anterior leaflet. Is it possible that in a fair amount of patients in this group, restriction was actually worsened by aggressive use of these techniques?

Dr Cikirikcioglu. Secondary and primary chordal transfer was used to correct the pseudoprolapse of the anterior leaflet secondary to the posterior leaflet retraction.
Dr Vricella. I can just see how if you actually start plicating or doing triangular resections, you can actually pull the 2 leaflets away from their coaptation area, so it was a concern of mine. The last question I had was: What were the findings at the time of the reoperation in the 3 patients with late failure in suspension group? The time to reintervention in this particular group was significantly shorter, it was 8 versus 36 months.

Dr Cikirikcioglu. It was our will to push the limits too much to repair these more severely affected rheumatic mitral valves in the suspension stitch group compared with the control group. I think the reoperations were not related to the techniques but to the severity of the rheumatic disorder.

Dr Vricella. Well, congratulations on your presentation. I think your excellent results underscore the importance of trying at all costs to repair valves in children rather than to replace them.

Dr Marshall Jacobs (Cleveland, Ohio). It is a very, very nice presentation of your technique and a nice analysis.

Echoing something that was in the primary discussant's comments, it appeared from your data that the aortic crossclamp time was virtually the same for the suspension stitch group and the other group, which means it did not take you long to do it. Also, I assume, based on your enthusiasm for the procedure, that your threshold for doing it is probably lowish, because you see very little downside.

On the other hand, like the previous discussant, I find it very surprising that you reported no cases in which you did a repair, came off cardiopulmonary bypass, found residual regurgitation that you thought might be attributed to immobility or tethering, and went back and solved that problem by placement of a tethering stitch. Have you had that experience? Were there any such cases that perhaps were not in this series?

Dr Cikirikcioglu. Based on our repair strategy, in occasional cases, we went back to solve the residual regurgitation. Also, as you noticed in the video, if you have residual regurgitation after repair, it is not logical to leave this residual regurgitation.

Our strategy is, first to obtain the best coaptation surface without any residual leak and then to see the dynamic final result on the transesophageal echocardiogram.

Dr Khanh Nguyen (New York, NY). I really enjoyed the presentation. I noticed that you only spend $1 \%$ of the time trying to do artificial chord placement. I am wondering whether you can release the tethered leaflet, lift it by just transecting the chord that is holding it down, and use Gore-Tex chords. Also, I would think that that would release the restriction significantly. Have you tried that technique?

Dr Cikirikcioglu. It is another option you can use. I mean, this technique can be useful also, I agree. But, in my opinion, our suspension technique is fast and reproducible and safe, and our midterm results are good. Usually these cases are coming to surgery at late stage with bad ventricular function. Thanks to the suspension technique, we are able to decrease the crossclamping time. For this reason, I agree with you, resection of retracted primary chordae and their replacement with an artificial chordae can also be used as an alternative technique, but we did not do that. 